\title{
Effect of Nano-SnS and Nano-MoS 2 on the Corrosion Protection Performance of the Polyvinylbutyral and Zinc-Rich Polyvinylbutyral Coatings
}

\author{
Zuopeng Qu ${ }^{1, *,+}$, Lei Wang ${ }^{1,+}$, Hongyu Tang ${ }^{2,3,+} \mathbb{C}$, Huaiyu Ye ${ }^{2}$ and Meicheng $\mathrm{Li}^{4}(\mathbb{D}$ \\ 1 National Engineering Laboratory for Biomass Power Generation Equipment, School of Renewable Energy, \\ North China Electric Power University, Beijing 102206, China \\ 2 Delft Institute of Microsystems and Nanoelectronics, Delft University of Technology, 2628 CD Delft, \\ The Netherlands \\ 3 Changzhou Institute of Technology Research for Solid State Lighting, Changzhou 213161, China \\ 4 State Key Laboratory of Alternate Electrical Power System with Renewable Energy Sources, School of \\ Renewable Energy School, North China Electric Power University, Beijing 102206, China \\ * Correspondence: z.qu@ncepu.edu.cn \\ + These authors contributed equally to this work.
}

Received: 20 May 2019; Accepted: 17 June 2019; Published: 30 June 2019

\begin{abstract}
In this paper, four composite coatings of nano-SnS/polyvinylbutyral (PVB), nano- $\mathrm{MoS}_{2} / \mathrm{PVB}$, nano-SnS-Zn/PVB, and nano-MoS $2-\mathrm{Zn} / \mathrm{PVB}$ were prepared, and their anti-corrosion mechanism was analyzed by experimental and theoretical calculations. The results of the electrochemical experiments show that the effect of nano-MoS 2 on the corrosion protection performance of PVB coating is better than that of nano-SnS in 3\% NaCl solution, and that the addition of $\mathrm{Zn}$ further enhances this effect, which is consistent with the results of weight loss measurements. Furthermore, the observation of the corrosion matrix by the field emission scanning electron microscope (FESEM) further confirmed the above conclusion. At last, the molecular dynamics (MD) simulation were carried out to investigate the anti-corrosion mechanism of the nanofillers/PVB composites for the copper surface. The results show that both nano-SnS and nano-MoS 2 are adsorbed strongly on the copper surface, and the binding energy of nano- $\mathrm{MoS}_{2}$ is larger than that of nano-SnS.
\end{abstract}

Keywords: anti-corrosion; tin sulfide (SnS); molybdenum disulfide $\left(\mathrm{MoS}_{2}\right)$; electrochemical test; composite coating

\section{Introduction}

Copper has good thermal and electrical properties, and is a commonly used material in marine engineering. It is often used in many parts such as hulls, pipes, electronic devices, etc. [1-3]. However, the corrosive nature of seawater and gas above the ocean severely limits the service life of copper $[4,5]$ and brings additional costs. Therefore, it is very meaningful to find a good way to delay the corrosion of copper. The protection of copper can be carried out in various ways such as inhibitor [6,7], film [8], coating $[9,10]$. The method of applying a composite coating to a metal substrate is convenient in application and low in cost, and is suitable for mass production in the industry. Thus many researchers have added various nanoparticles as fillers in polyvinylbutyral (PVB) as a physical barrier to enhance the barrier effect of the coating on water, oxygen, and other corrosive media [10].

Conventional graphene materials have been used as fillers in anti-corrosion coatings due to their high surface-to-volum ratio and excellent physical properties. However, they have a 'corrosion-promoting activity' when the coating is broken because of good electrical conductivity $[9,11]$, which promotes the corrosion of the metal substrate. As a semiconductor material, tin sulfide (SnS) 
has good chemical stability and will not cause harm to human health and environment [12]. It is widely used in optoelectronics and sensors [13-16]. However, there are currently few reports on anti-corrosion applications for SnS. SnS has a very large resistivity and therefore may exhibit better corrosion resistance compared to graphene. $\mathrm{MoS}_{2}$ is a transition metal disulfide with a variety of excellent physical properties. It has a layered structure and can be used to construct a variety of one-, two-, and three-dimensional materials [17-23], which has broad application prospects. In addition, $\mathrm{MoS}_{2}$ has good hydrophobicity $[24,25]$, which has been used by researchers to make composite coatings or to modify existing graphene products $[17,26]$. Therefore, we consider adding nano-MoS 2 as a filler to the coating to verify its protection against metallic copper. Moreover, nano- $\mathrm{Zn}$, as an active metal, can be used as a cathodic protection in the coating to improve the protective ability of the coating. At present, many researchers have used Zn or zinc ions as additives to modify coatings $[27,28]$ to enhance the protection of metals.

Our current work aims to study and compare the corrosion protection performance of nano-SnS and nano-MoS 2 on polyvinylbutyral (PVB) coatings and zinc-rich PVB coatings. Weight loss, potentiodynamic polarization, and electrochemical impedance spectroscopy (EIS) were used to evaluate the anti-corrosion performance of nano-SnS/PVB, nano-MoS $/ \mathrm{PVB}$, nano-SnS-Zn/PVB and nano- $\mathrm{MoS}_{2}-\mathrm{Zn} / \mathrm{PVB}$ coatings at first. In addition, field emission scanning electron microscope (FESEM) was used to characterize the morphology of the copper after corrosion to verify the test results. Furthermore, molecular dynamics (MD) simulations were used to study the adsorption properties of nano-SnS/PVB and nano-MoS $2 / \mathrm{PVB}$ on copper surfaces.

\section{Experimental}

\subsection{Material and Sample Preparation}

Some of the key materials used in this experiment are shown in Table 1, in which the average particle size of the nanoparticles is $50 \mathrm{~nm}$.

Table 1. Materials used for preparing composite coatings.

\begin{tabular}{ccc}
\hline Material & Manufacturer & Label \\
\hline Polyvinylbutyral & MACKLIN & P815775 \\
Tin sulfide & 6Carbon Tech. Shenzhen & SC-CRYSTAL-SNS \\
Molybdenum disulfide & HANLANE & MoS $_{2}-50$ \\
Zinc & HANLANE & Zn-50 $^{2}$ \\
\hline
\end{tabular}

Nano-SnS $(0.1 \mathrm{~g})$ was sonicated in $10 \mathrm{~mL}$ of methanol for more than $5 \mathrm{~h}$ to form a suspension. Then, $1.0 \mathrm{~g}$ of PVB powder was added to the suspension, and the mixture was thoroughly stirred for more than $36 \mathrm{~h}$ on a magnetic stirrer to prepare a uniform paint, and the resultant material was allowed to stand for use. The molecular structure of PVB is shown in Figure 1. Nano-MoS $2 / \mathrm{PVB}$, nano-SnS-Zn/PVB, and nano- $\mathrm{MoS}_{2}-\mathrm{Zn} / \mathrm{PVB}$ coatings were prepared in the same manner, wherein the amount of $\mathrm{Zn}$ added was $0.05 \mathrm{~g}$. The copper piece with a thickness of $0.05 \mathrm{~mm}$ was cut to a size of $1.0 \mathrm{~cm} \times 1.0 \mathrm{~cm}$, and it was carefully polished with 400,800 , and 2,000 mesh emerald paper. After the sanding was completed, the copper sheets were ultrasonically cleaned with ultrapure water for more than $5 \mathrm{~min}$, then degreased with acetone and air dried naturally in a fume hood. The copper sheet was dipped into the prepared paint for $40 \mathrm{~s}$ and then taken out at a rate of about $0.5 \mathrm{~mm} \mathrm{~s}^{-1}$. The samples were air dried naturally in a fume hood for $24 \mathrm{~h}$. The thickness of the prepared coatings was essentially the same and they were controlled at $19.3 \pm 1.2 \mu \mathrm{m}$, which was measured with a portable coating thickness gauge (EC-770, YOWEXA, Shenzhen, China). Some of the copper sheets were sealed with 705 silicone rubber on the back, leaving $1.0 \mathrm{~cm}^{2}$ of working surface for electrochemical experiments, while the rest retained double working faces for weight loss measurements. $\mathrm{A} \mathrm{NaCl}$ solution having a 
concentration of $3.0 \%$ was prepared for electrochemical experiments and weight loss measurements. All experiments were performed at room temperature (about $293 \mathrm{~K}$ ).

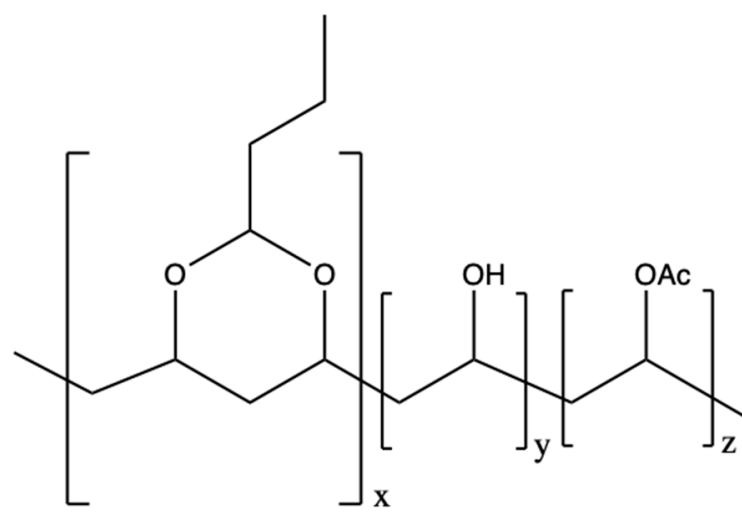

Figure 1. Molecular structure of PVB used in this work.

\subsection{Weight Loss Measurements}

Weight loss measurements were carried out in glass dishes at $293 \mathrm{~K}$. Samples, without and with different coatings, prepared in triplicate were each immersed in a $3.0 \% \mathrm{NaCl}$ solution. The samples were continuously immersed for 35 days, then soaked in methanol to dissolve the surface coating and thoroughly rinsed in $0.1 \mathrm{M} \mathrm{HCl}$, water, and acetone in order to remove corrosion products and other impurities. The copper sheets were weighed with an analytical balance after drying. The average corrosion rate was finally calculated by the immersion time and the weight loss of each sample.

\subsection{Electrochemical Experiments}

The electrochemical experiments in this paper are performed using a conventional three-electrode system. The copper piece to be tested was the working electrode, the saturated calomel electrode (SCE) was used as the reference electrode, and the platinum mesh electrode $(2.0 \mathrm{~cm} \times 2.0 \mathrm{~cm})$ was used as the counter electrode. The CHI660C electrochemical workstation was used for the electrochemical measurements. Prior to each test, the working electrode was immersed in an etching medium for about $30 \mathrm{~min}$ at an open circuit potential (OCP) until the OCP value reached an almost constant state. EIS measurements were made under open circuit potential with a sweep frequency range of $10 \mathrm{mHz}-100 \mathrm{kHz}$ and an amplitude of $5 \mathrm{mV}$ AC sinusoidal disturbance. The EIS data were analyzed and fitted by Zsimpwin 3.60 software. Furthermore, a polarization experiment was performed at a potential range of $\pm 250 \mathrm{mV}$ relative to the OCP at a scan rate of $2 \mathrm{mV} \mathrm{s}^{-1}$. Each sample was tested more than 4 times to ensure the reproducibility of the experiments.

\subsection{Scanning Electron Microscope (SEM) Observations}

Scanning electron microscopy (SEM, JSM6490LV, JEOL, Tokyo, Japan) was used to observe and analyze the copper matrix without and with different coatings at 293 K. Prior to observation, all samples were immersed in a $3.0 \% \mathrm{NaCl}$ solution at $293 \mathrm{~K}$ for 10 days, and then the surface coated samples were immersed in anhydrous methanol to remove the surface coating.

\subsection{Theoretical Study}

In order to further discuss the interaction between the PVB/nanosheets composites and copper surface, molecular dynamics (MD) simulation were carried out to model the adsorption structure of SnS-PVB and $\mathrm{MoS}_{2}$-PVB system on copper (111) surface. MD simulations were performed using commercially available software, Material Studio 8.0, purchased from Accelrys Inc (San Diego, CA, USA). The structure of PVB chain and molecules of $\mathrm{SnS}$ or $\mathrm{MoS}_{2}$ nanosheet were generated and optimized through the Forcite module. The PVB model was prepared with the dimensions of 
$28 \times 30 \times 126 \AA$, with an initial density of $1.05 \mathrm{~g} \mathrm{cc}^{-1}$, which agrees well with experimental data of $1.07 \mathrm{~g} \mathrm{cc}^{-1}$ [29]. The energy minimized structures of PVB ( 2 chains) and nanosheets were used for the construction of different amorphous cells. The optimization procedure follows convergence criteria: $2.0 \times 10^{-5} \mathrm{kcal} \mathrm{mol}^{-1}$ for energy, $0.001 \mathrm{kcal} \mathrm{mol}^{-1} \AA^{-1}$ for force, and $1.0 \times 10^{-5}$ for displacement. After the geometry optimization, molecular dynamic calculation with constant number of particles, volume and temperature (NVT) and Universal force field (UFF) [30] was performed at time step of $1.0 \mathrm{fs}$ up to total $3.0 \mathrm{~ns}$, among which Andersen algorithm themostat with 1.0 Collision ratio was used to maintain the temperature of the system at around $298 \mathrm{~K}$. The interaction energy $E_{\text {Interaction, }}$ post to equilibration is then calculated using Equation (1):

$$
E_{\text {Interaction }}=E_{\text {Total }}-\left(E_{C u}+E_{\text {composite }}\right) \text {, }
$$

where $E_{\text {Total }}$ is the combined energy of the $C u$ surface and the PVB-nanosheets system, $E_{C u}$ is the energy of the solo $\mathrm{Cu}$ surface, and $E_{\text {composite }}$ is the energy of the PVB-nanosheets system taken independently. Based on Equation (1), it can be stated that the more negative the value, the better is the adhesion the composites coating applied on the surface.

\section{Results and Discussion}

\subsection{Weight Loss Measurements}

The corrosion resistance of various coatings to copper was investigated by weight loss measurements after immersion in a $3.0 \% \mathrm{NaCl}$ solution at $293 \mathrm{~K}$ for 35 days. The corrosion rates $(\omega$, $\mathrm{mg} \mathrm{m}^{-2} \mathrm{~h}^{-1}$ ) and protective efficiency $\left(\eta_{w}\right)$ of these coatings were calculated as follows, and the results are shown in Table 2,

$$
\begin{gathered}
\omega=\frac{m_{0}-m}{A \tau}, \\
\eta_{w} \%=\frac{\omega_{0}-\omega}{\omega_{0}} \cdot 100,
\end{gathered}
$$

where $A$ is the total surface area of the sample; $m_{0}$, and $m$ are the weights of the sample before and after immersion in the corrosive solution, respectively; $\tau$ is the soaking time; and $\omega_{0}$ and $\omega$ are the corrosion rates of the copper samples containing and containing the coating, respectively.

Table 2. Corrosion rate and protection efficiency of copper sheets without and with different coatings in $3.0 \% \mathrm{NaCl}$ solution at $293 \mathrm{~K}$.

\begin{tabular}{ccc}
\hline Coating & $\boldsymbol{\omega}\left(\mathbf{m g ~ m}^{-\mathbf{2}} \mathbf{h}^{-\mathbf{1}}\right)$ & $\eta_{w}(\%)$ \\
\hline Blank & 59.52 & - \\
PVB & 41.67 & 30 \\
nano-SnS & 23.81 & 60 \\
nano-SnS-Zn/PVB & 15.48 & 74 \\
nano-MoS $/$ PVB & 20.24 & 66 \\
nano-MoS 2 -Zn/PVB & 14.29 & 76 \\
\hline
\end{tabular}

As shown in Table 2, the corrosion rate of the coated copper sheet sample was smaller than that of the uncoated copper sheet sample. Compared to pure PVB coatings, copper samples with nanofiller coatings have a lower corrosion rate and higher protection efficiency. Furthermore, the addition of $\mathrm{Zn}$ can improve the protection efficiency of the coating by more than $10 \%$. It is worth noting that for the nano-MoS $2-\mathrm{Zn} / \mathrm{PVB}$ coating, the $\eta_{w}$ value is as high as $76 \%$, which is $46 \%$ higher than the pure PVB coating. 


\subsection{Polarization Curve}

The Tafel polarization curves of copper electrodes coated with different coatings measured in $3 \% \mathrm{NaCl}$ solution are shown in Figure 2. We obtained the main electrochemical parameters by extrapolation, including corrosion potential $\left(E_{\text {corr }}\right)$, corrosion current density $\left(i_{\text {corr }}\right)$, anode and cathode Tafel slope $\left(\beta_{a}, \beta_{c}\right)$, and protection efficiency $\left(\eta_{P}\right)$. Their values were listed in Table 3 . The value of the protection efficiency $\eta$ is calculated as follows,

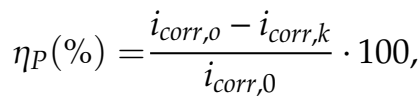

where $i_{\text {corr }, o}\left(\mathrm{~A} \mathrm{~cm}^{-2}\right)$ is the corrosion current density of the uncoated copper sample, $i_{\text {corr, } k}\left(\mathrm{~A} \mathrm{~cm}^{-2}\right)$ is the corrosion current density of the sample containing the different composite coating.

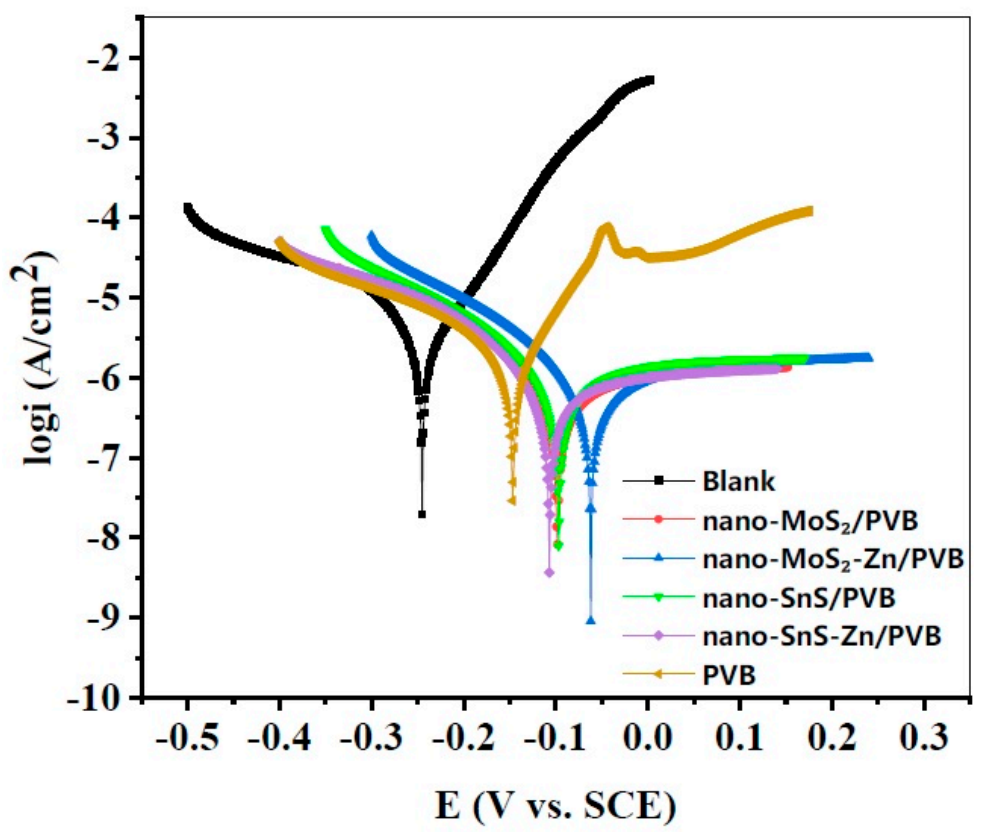

Figure 2. Tafel curve recorded for copper samples without and with different coatings in $3.0 \% \mathrm{NaCl}$ solution at $293 \mathrm{~K}$.

Table 3. Electrochemical parameters for copper sample without and with different coatings in $3.0 \%$ $\mathrm{NaCl}$ solution at $293 \mathrm{~K}$.

\begin{tabular}{|c|c|c|c|c|c|c|}
\hline Coating & $\begin{array}{c}E_{\text {corr }} \\
(\mathrm{mV} \text { per } \mathrm{SCE})\end{array}$ & $\begin{array}{c}i_{\text {corr }} \\
\left(\mu \mathrm{A} \mathrm{cm}^{-2}\right)\end{array}$ & $\begin{array}{c}\beta_{c} \\
\left(\mathrm{mVV} \operatorname{dec}^{-1}\right)\end{array}$ & $\begin{array}{c}\beta_{a} \\
\left(\mathrm{mV} \mathrm{dec}^{-1}\right)\end{array}$ & $\begin{array}{l}\text { Crate } \\
\text { (mpy) }\end{array}$ & $\eta_{P}(\%)$ \\
\hline Blank & -245 & 2.185 & 60 & 55 & 1.00 & - \\
\hline PVB & -147 & 1.839 & 179 & 75 & 0.85 & 15.8 \\
\hline nano-SnS/PVB & -97 & 0.921 & 105 & 280 & 0.42 & 57.9 \\
\hline nano-SnS-Zn/PVB & -107 & 0.757 & 99 & 317 & 0.35 & 65.4 \\
\hline nano-MoS $2 / \mathrm{PVB}$ & -98 & 0.710 & 102 & 297 & 0.33 & 67.5 \\
\hline nano-MoS $2-\mathrm{Zn} / \mathrm{PVB}$ & -62 & 0.591 & 84 & 190 & 0.27 & 72.9 \\
\hline
\end{tabular}

Figure 2 shows that the current densities of the samples with coatings are significantly lower than that of the uncoated copper. More importantly, the coating with the nanofiller exhibited a significantly lower current density than the pure PVB coating. This indicates that after the surface of the copper sheet is coated, its corrosion strength and corrosion rate, in $3 \% \mathrm{NaCl}$ becomes lower.

According to Table 3, the current density $\left(i_{\text {corr }}\right)$ of $\mathrm{MoS}_{2}$ is lower than that of SnS, and the $i_{\text {corr }}$ higher compared with the corresponding Zn-containing composite coatings of SnS and $\mathrm{MoS}_{2}$. This 
indicates that the corrosion protection ability of $\mathrm{MoS}_{2}$ is better than that of SnS, and the addition of $\mathrm{Zn}$ has a certain improvement effect on the protective ability of the coating. The $\eta_{P}$ value of the sample with the composite coating increased by more than $40 \%$ compared to the sample with a pure PVB coating, and the efficiency value of the nano- $\mathrm{MoS}_{2}-\mathrm{Zn} / \mathrm{PVB}$ coating was the largest, reaching $72.9 \%$. The experimental results show that the composite coating has a significant protective effect on the metal matrix, which is in line with the result of weight loss measurements.

\subsection{Electrochemical Impedance Spectroscopy (EIS)}

In order to study the corrosion mechanism of the metal and the improvement of the corrosion resistance of the coating, we measured the electrochemical impedance spectroscopy of copper with pure PVB coatings and different nanofiller composite coatings. The experiments were carried out in 3.0\% NaCl solution. As shown in Figure 3a, the Nyquist plot of the PVB coated and uncoated copper sheet show an incomplete semicircle in the high frequency region and an approximate straight line in the subsequent low frequency range. In general, the high frequency region semicircle is related to the charge transfer resistance $\left(R_{c t}\right)$ and the double layer capacitance $\left(C_{d l}\right)$. The low frequency impedance is the Warburg impedance $(W)$, which means the diffusion of dissolved oxygen or soluble cuprous chloride complexes during the corrosion process.
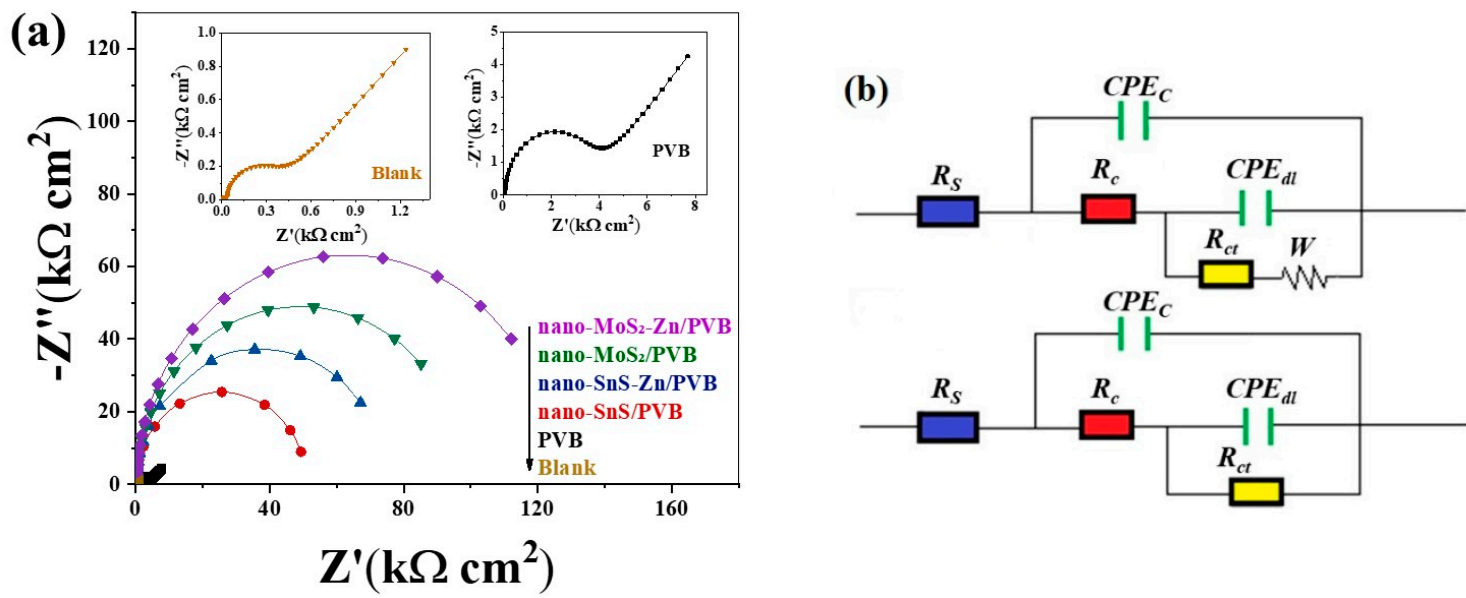

Figure 3. (a) Nyquist plots for copper samples in $3.0 \% \mathrm{NaCl}$ solution without and with different coatings at $293 \mathrm{~K}$ and (b) equivalent circuit diagrams for fitting Electrochemical Impedance Spectroscopy (EIS) data.

Figure 3a shows that after the addition of the nanofiller, the shape of the curve appears to be approximately semicircular, and the Warburg impedance in the low frequency region disappears. This indicates that the addition of nanofiller inhibits the diffusion of dissolved oxygen and cuprous chloride complexes. At this time, the corrosion of copper depends on the charge transfer process. The order of the diameter of the semicircle obtained by different coating samples is: nano-MoS $2-\mathrm{Zn} / \mathrm{PVB}>$ nano-MoS $2 / \mathrm{PVB}>$ nano-SnS-Zn/PVB $>$ nano-SnS/PVB, and the diameter of the semicircle of the sample added with $\mathrm{Zn}$ is obviously increased. According to this result, it can be judged that the nano-MoS ${ }_{2}$ filler is better than the nano-SnS for the corrosion protection performance of the PVB coatings and the addition of $\mathrm{Zn}$ particles further improves the corrosion resistance of the composite coatings.

In order to quantitatively compare the corrosion inhibition properties of different coatings, we further fit the EIS data using the equivalent circuit diagram shown in the inset of Figure $3 b$, and the resulting electrochemical parameters are listed in Table 4 , where $R_{s}$ is the solution resistance, $R_{c}$ is the resistance of the coating on the copper working surface, $R_{c t}$ is the charge transfer resistance, and $W$ is the Warburg impedance. $C P E_{c}$ and $C P E_{d l}$ are constant phase angle elements representing the coating 
capacitance $\left(C_{c}\right)$ and the double layer capacitance $\left(C_{d l}\right)$, respectively. The impedance of these circuits can be expressed as follows [31],

$$
\begin{gathered}
Z_{W}=R_{S}+\frac{1}{j w C P E_{c}+\frac{1}{R_{c}}+\frac{1}{j w C P E_{d l}+\frac{1}{R_{c t}+w}}} \\
Z=R_{S}+\frac{1}{j w C P E_{c}+\frac{1}{R_{c}}+\frac{1}{j w C P E_{d l}+\frac{1}{R_{c t}}}}
\end{gathered}
$$

Table 4. Electrochemical parameters of EIS in copper samples without and with different coatings in

\begin{tabular}{|c|c|c|c|c|c|c|c|}
\hline Coating & $\begin{array}{c}R_{s} \\
\left(\Omega \mathrm{cm}^{2}\right)\end{array}$ & $\begin{array}{c}R_{c} \\
\left(\mathrm{k} \Omega \mathrm{cm}^{2}\right)\end{array}$ & $\begin{array}{c}R_{c t} \\
\left(\mathrm{k} \Omega \mathrm{cm}^{2}\right)\end{array}$ & $\begin{array}{c}C_{c} \\
\left(\mu \mathrm{F} \mathrm{cm}^{-2}\right)\end{array}$ & $\begin{array}{c}C_{d l} \\
\left(\mu \mathrm{F} \mathrm{cm}^{-2}\right)\end{array}$ & $W$ & $\eta_{E}(\%)$ \\
\hline Blank & 7.94 & 0.04 & 0.32 & 13.08 & 128.30 & 0.002902 & - \\
\hline PVB & 19.50 & 0.07 & 3.50 & 1.84 & 18.17 & 0.000620 & 90.86 \\
\hline nano-SnS/PVB & 18.14 & 0.11 & 50.84 & 2.69 & 54.21 & - & 99.37 \\
\hline nano-SnS-Zn/PVB & 22.54 & 0.30 & 74.36 & 2.49 & 69.49 & - & 99.57 \\
\hline nano-MoS $2 / \mathrm{PVB}$ & 20.07 & 0.26 & 97.84 & 3.07 & 60.39 & - & 99.67 \\
\hline nano-MoS $2-\mathrm{Zn} / \mathrm{PVB}$ & 25.09 & 0.30 & 126.20 & 1.92 & 43.34 & - & 99.75 \\
\hline
\end{tabular}
$3.0 \% \mathrm{NaCl}$ solution at $293 \mathrm{~K}$.

The impedance of the CPE is defined as follows [31],

$$
Z_{C P E}=\frac{w^{-n}}{Y\left(\frac{\cos n \pi}{2}+j \frac{\sin n \pi}{2}\right)^{n}}
$$

where $Y$ is the modulus of the $C P E, w$ is the angular frequency, $j$ is the imaginary number, and $n$ is the deviation parameter. The $\eta$ values of the copper electrode coatings in these $3 \% \mathrm{NaCl}$ solutions are calculated as follows,

$$
\eta_{E}(\%)=\frac{R_{c t}-R_{c t, 0}}{R_{c t}} \cdot 100
$$

where $R_{c t}$ and $R_{c t, 0}$ are the charge transfer resistances of copper samples with and without various coatings in $3 \% \mathrm{NaCl}$ solution, respectively.

As can be seen from Table 4 , the $R_{c}$ and $R_{c t}$ values of the nano-MoS $/ \mathrm{PVB}$ coated samples were larger than those of nano-SnS/PVB, and these values improved in the samples to which $\mathrm{Zn}$ was added. This again demonstrates that nano- $\mathrm{MoS}_{2}$ enhances the corrosion resistance of the coating better than nano-SnS, and the addition of $\mathrm{Zn}$ further enhances the corrosion resistance of the coating. In addition, all copper samples with coatings incorporating nanofillers had $\eta_{E}$ values above $99 \%$, which is a significant increase compared to samples with pure PVB coatings. These demonstrate that the use of nanoparticles as a filler can effectively enhance the corrosion resistance of polymer coatings. The trend of these values is basically consistent with the weight loss measurements results. Several typical corrosion resistant materials and their values of $\eta_{E}$ obtained in a $\mathrm{NaCl}$ solution are listed in Table 5 . The higher $\eta_{E}$ values further highlight the superior corrosion resistance of the composite coatings in this study compared to these materials $[6,32,33]$. 
Table 5. Anti-corrosion materials and their protection efficiency $\left(\eta_{E}\right)$ by EIS test in 3.0-3.5\% $\mathrm{NaCl}$ solution.

\begin{tabular}{ccc}
\hline Classification & Samples & $\eta_{E} \mathbf{( \% )}$ \\
\hline Silicon carbide composite & POA-SiC/EP & 87.54 \\
Metal Organic Framework & ATT/ZIF-8 & 97.3 \\
Organic inhibitor & polyaspartic acid & 86.8 \\
\hline
\end{tabular}

\subsection{SEM Analyses}

At $293 \mathrm{~K}$, SEM high-resolution photographs of copper samples without and with different coatings immersed in $3 \% \mathrm{NaCl}$ solution for 10 days are shown in Figure 4. After the copper with pure PVB coating (Figure $4 \mathrm{~b}$ ) was immersed in $3 \% \mathrm{NaCl}$ solution, the substrate experienced severe corrosion with many obvious large-area corrosion marks. Although the nano-SnS/PVB sample (Figure 4c) also showed local corrosion, the degree of corrosion was lower than that of the pure PVB coating sample, and large-area local corrosion disappeared after the addition of $\mathrm{Zn}$ (Figure $4 \mathrm{~d}$ ). In addition, the nano-MoS $2 / \mathrm{PVB}$ sample (Figure 4e) exhibited slight signs of corrosion, while the substrate surface of the nano-MoS $2-\mathrm{Zn} / \mathrm{PVB}$ sample (Figure $4 \mathrm{f}$ ) was well protected.

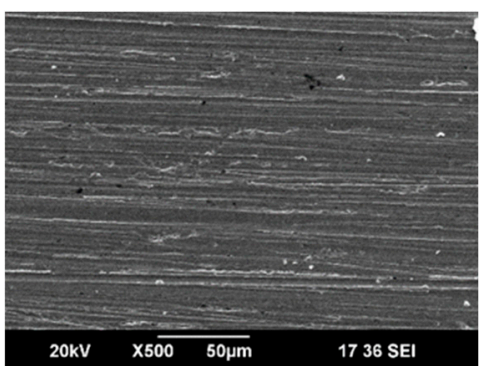

(a)

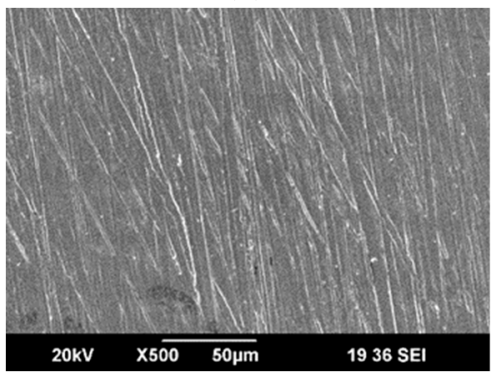

(d)

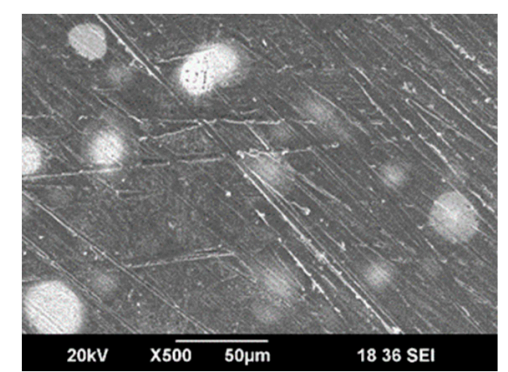

(b)

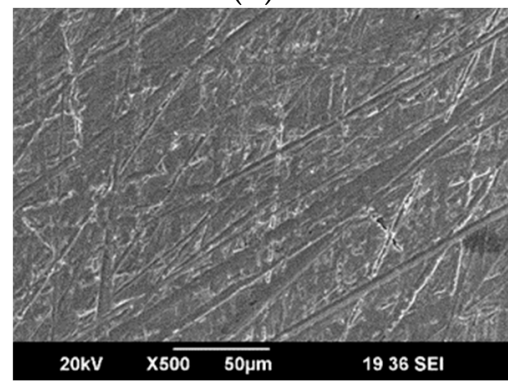

(e)

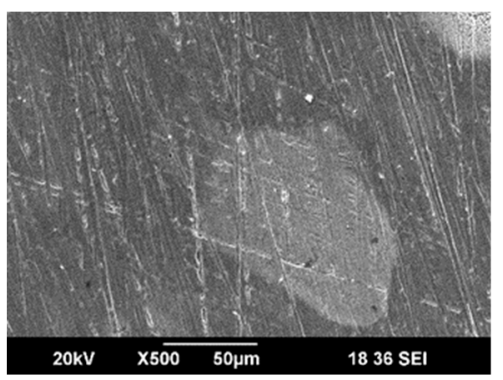

(c)

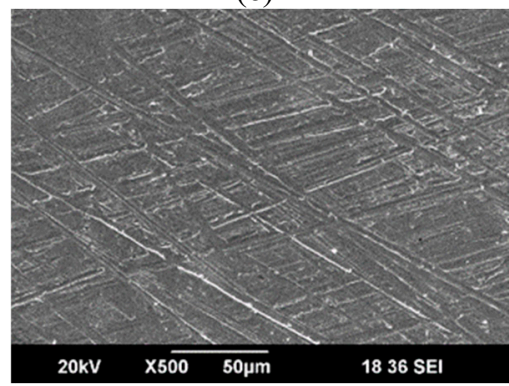

(f)

Figure 4. SEM images of (a) freshly polished copper specimen and the specimens immersed in $3 \% \mathrm{NaCl}$ solution with (b) PVB, (c) nano-SnS/PVB, (d) nano-SnS-Zn/PVB, (e) nano-MoS $2 / \mathrm{PVB}$, and (f) nano-MoS $2-\mathrm{Zn} / \mathrm{PVB}$ coating for10 days at $293 \mathrm{~K}$.

The observation of these high-definition pictures proves that $\mathrm{MoS}_{2}$ can improve the anti-corrosion performance of PVB more than SnS, and the addition of $\mathrm{Zn}$ further enhances this performance. The SEM analysis further validated the results of electrochemical experiments and weight loss measurements.

\subsection{Corrosion Mechanism Analysis}

The corrosion process of $\mathrm{Cu}$ in $\mathrm{NaCl}$ solution has been described in numerous reports [34-37]. As we all know, in the corrosion process of copper with $\mathrm{NaCl}$ solution as the medium, the cathodic reaction is represented by the reduction of oxygen $[1,38]$,

$$
\mathrm{O}_{2}+4 \mathrm{e}+2 \mathrm{H}_{2} \mathrm{O} \rightarrow 4 \mathrm{OH}^{-}
$$


The anode undergoes the following series of complex reactions [39],

$$
\begin{gathered}
\mathrm{Cu} \rightarrow \mathrm{Cu}^{+}+\mathrm{e}, \\
\mathrm{Cu}^{+}+\mathrm{Cl}^{-} \rightarrow \mathrm{CuCl}^{-} \\
\mathrm{CuCl}+\mathrm{Cl}^{-} \rightarrow \mathrm{CuCl}_{2}^{-}, \\
\mathrm{CuCl}_{2}^{-} \rightarrow \mathrm{Cu}^{2+}+2 \mathrm{Cl}^{-}+\mathrm{e}
\end{gathered}
$$

The insulation of the composite coating inhibits the transfer of current, hinders the formation of a closed loop between the substrate and the etching solution, and reduces the corrosion rate. Besides, the nanoparticle filler acts as a physical barrier in the polymer, preventing the penetration of $\mathrm{O}_{2}$ and $\mathrm{H}_{2} \mathrm{O}$ into the metal, and the diffusion of $\mathrm{CuCl}_{2}^{-}$into the $3 \% \mathrm{NaCl}$ solution. Moreover, for the $\mathrm{Zn}$-added coating, since $\mathrm{Zn}$ has a lower electronegativity than $\mathrm{Cu}, \mathrm{Zn}$ is first corroded in the system, which delays the oxidation process of the anode $\mathrm{Cu}$ as shown in Equation (10). This further explains the test results of the EIS. The analysis of corrosion and protection mechanisms is consistent with Han et al. [9,40].

\subsection{Molecular Dynamics Simulation}

As shown in Figures 5 and 6, after sufficient relaxation and of equilibrium the PVB-nanosheets system, two types of composites slowly approached to $\mathrm{Cu}$ surface, indicating that the combined energy of the $\mathrm{Cu}$ surface and the PVB-nanosheets system is large. The interaction energy $E_{\text {Interaction }}$ of pure PVB, $\mathrm{SnS} / \mathrm{PVB}, \mathrm{MoS}_{2} / \mathrm{PVB}$ with $\mathrm{Cu}$ surface are listed in Table 6 . All the energies obtained have been found to be negative in sign, which means that all the formulated coatings show sufficient binding to the surface. The $E_{\text {Interaction }}$ of $\mathrm{MoS}_{2} / \mathrm{PVB}$ composite $\left(-1,838.253 \mathrm{kcal} \mathrm{mol}^{-1}\right)$ is larger than that of SnS/PVB composites $\left(-1,074.433 \mathrm{kcal} \mathrm{mol}^{-1}\right)$ and PVB coatings $\left(-852.33 \mathrm{kcal} \mathrm{mol}^{-1}\right)$, indicating that the anti-corrosion behavior of $\mathrm{MoS}_{2} / \mathrm{PVB}$ composite coatings is better than that of SnS/PVB and pure PVB. The MD simulation results are in good agreement with the results obtained from potentiodynamic polarization measurements and EIS, which is further confirm that the excellent anti-corrosion performance of $\mathrm{MoS}_{2} / \mathrm{PVB}$ is attributed to its high interfacial binding energy. In addition, the $E_{\text {Interaction }}$ is larger than that of previous work, such as $-500 \mathrm{kcal} \mathrm{mol}^{-1}$ of Polyvinyl acetate (PVAc)-Perfluorooctane (PFO) systems and $-27.3 \mathrm{kcal} \mathrm{mol}^{-1}$ graphene-based polymer coatings [41,42], which reveals the $\mathrm{MoS}_{2} / \mathrm{PVB}$ and SnS/PVB composites coatings exhibit excellent corrosion protection performance than many nanosheets-polymer composites.

Table 6. The simulated surface energy for different systems at $298 \mathrm{~K}$.

\begin{tabular}{cc}
\hline System & Interaction Energy (kcal mol $\mathbf{~ m}^{\mathbf{1}}$ ) \\
\hline $\mathrm{Cu}+\mathrm{PVB}$ & -852.33 \\
$\mathrm{Cu}+\mathrm{MoS}_{2} / \mathrm{PVB}$ & -1838.253 \\
$\mathrm{Cu}+\mathrm{SnS} / \mathrm{PVB}$ & -1074.433 \\
\hline
\end{tabular}




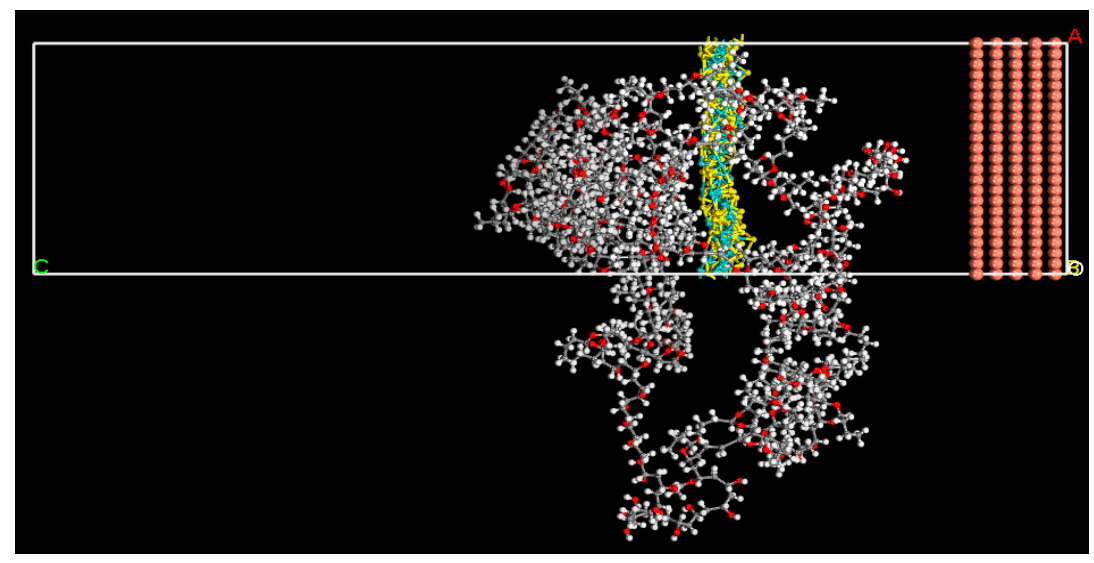

(a)

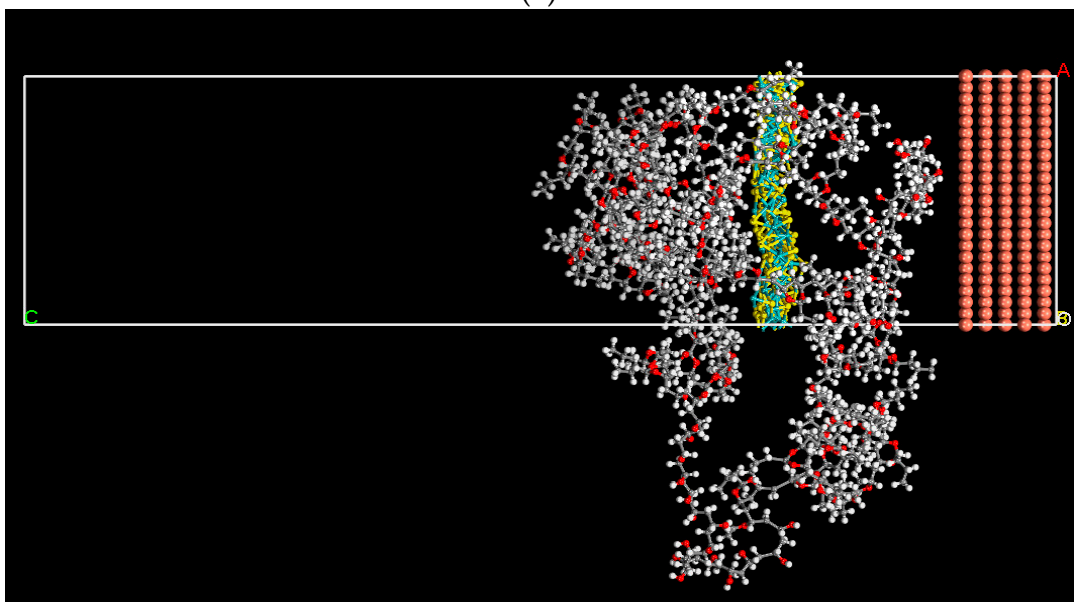

(b)

Figure 5. Illustration of (a) the $\mathrm{MoS}_{2}$-PVB system consisting of copper (111) crystal as the substrate (shown in brown spheres) and PVB containing $10 \% \mathrm{MoS}_{2}$ at time 0 ps. (b) Final $\mathrm{MoS}_{2}$-PVB system post-MD run of 500 ps.

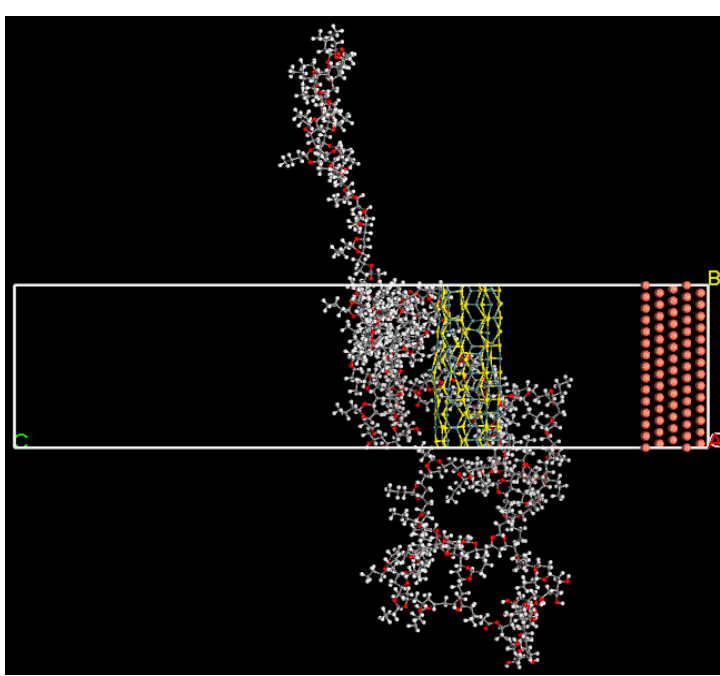

(a)

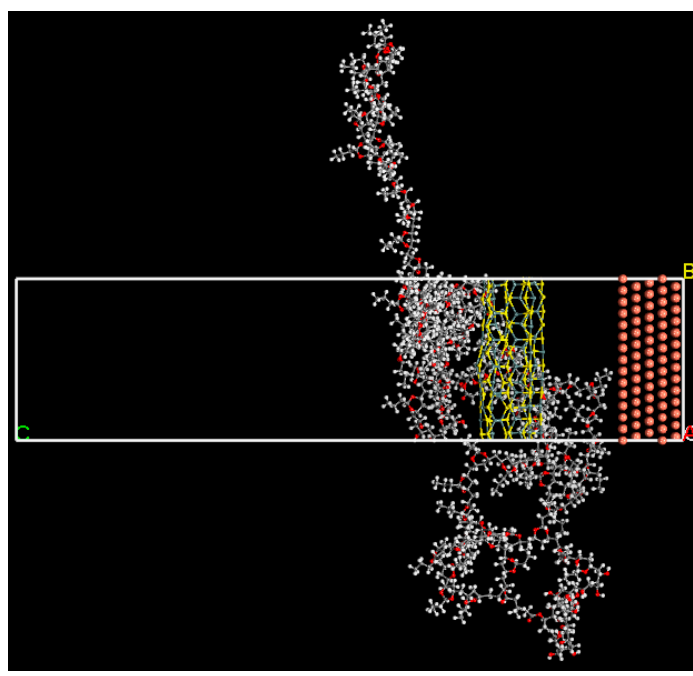

(b)

Figure 6. Illustration of (a) the SnS-PVB system consisting of copper (111) crystal as the substrate (shown in brown spheres) and PVB containing $10 \%$ SnS at time 0 ps. (b) Final SnS-PVB system post-MD run of 500 ps. 


\section{Conclusions}

The anti-corrosion performance of nano-SnS/PVB, nano- $\mathrm{MoS}_{2} / \mathrm{PVB}$, nano-SnS-Zn/PVB, and nano-MoS $2-\mathrm{Zn} / \mathrm{PVB}$ was studied by experiments and theoretical calculations. All four coatings have good corrosion protection performance and their protective efficiencies calculated from the weight loss and polarization curves are consistent. Moreover, the Nyquist plot and fit to the EIS data indicate that nano- $\mathrm{MoS}_{2} / \mathrm{PVB}$ has better anti-corrosion performance than nano-SnS/PVB. The addition of $\mathrm{Zn}$ further enhances this performance. These can be further confirmed by FESEM observation. Compared to graphene-based films or other composite coatings with nanomaterials as fillers, the composite coatings prepared herein have higher $\eta_{P}$ and $R_{c t}$ values $[43,44]$, meaning that the coatings have better corrosion resistance. At last, the results of the molecular dynamics (MD) simulation show that both nano-SnS and nano-MoS 2 are adsorbed strongly on the copper surface, and the binding energy of nano-MoS $\mathrm{S}_{2}$ larger than that of nano-SnS. Furthermore, compared to some other studies, these composite coatings have a larger interaction energy $E_{\text {Interaction }}$ with the copper surface. There are still many aspects of this research that need to be explored and improved in future work, such as sample preparation methods and coating modification.

Author Contributions: Conceptualization, Z.Q., L.W., and H.T.; methodology, L.W. and H.T.; software, H.T.; validation, Z.Q. and H.T.; formal analysis, L.W. and H.T.; investigation, Z.Q.; resources, Z.Q. and M.L.; data curation, L.W. and H.T.; writing-Original draft preparation, Z.Q., L.W., and H.T.; writing-Review and editing, Z.Q., H.T., and H.Y.; visualization, L.W.; supervision, M.L.; project administration, Z.Q.; funding acquisition, Z.Q.

Funding: This work was supported by the Fundamental Research Funds for the Central Universities 2014 MS30.

Acknowledgments: The authors would like to thank Peng Peng for his technical support.

Conflicts of Interest: The authors declare no conflict of interest.

\section{References}

1. Qiang, Y.; Zhang, S.; Xu, S.; Yin, L. The effect of 5-nitroindazole as an inhibitor for the corrosion of copper in a $3.0 \% \mathrm{NaCl}$ solution. RSC Adv. 2015, 5, 63866-63873. [CrossRef]

2. Al Kharafi, F.M.; Ghayad, I.M.; Abdallah, R.M. Corrosion inhibition of copper in seawater by 4-amino-4h-1,2,4-triazole-3-thiol. Corrosion 2013, 69, 58-66. [CrossRef]

3. Amin, M.A. Weight loss, polarization, electrochemical impedance spectroscopy, SEM and EDX studies of the corrosion inhibition of copper in aerated $\mathrm{NaCl}$ solutions. J. Appl. Electrochem. 2006, 36, 215-226. [CrossRef]

4. Ran, M.; Zheng, W.; Wang, H. Fabrication of superhydrophobic surfaces for corrosion protection: A review. Mater. Sci. Technol. 2019, 35, 313-326. [CrossRef]

5. Heakal, F.E.-T.; Fekry, A.M.; Fatayerji, M.Z. Influence of halides on the dissolution and passivation behavior of AZ91D magnesium alloy in aqueous solutions. Electrochim. Acta 2009, 54, 1545-1557. [CrossRef]

6. Zeino, A.; Abdulazeez, I.; Khaled, M.; Jawich, M.W.; Obot, I.B. Mechanistic study of polyaspartic acid (PASP) as eco-friendly corrosion inhibitor on mild steel in 3\% NaCl aerated solution. J. Mol. Liq. 2018, 250, 50-62. [CrossRef]

7. Qiang, Y.; Zhang, S.; Xu, S.; Li, W. Experimental and theoretical studies on the corrosion inhibition of copper by two indazole derivatives in $3.0 \% \mathrm{NaCl}$ solution. J. Colloid Interface Sci. 2016, 472, 52-59. [CrossRef]

8. Xu, S.; Gao, X.; Sun, J.; Hu, M.; Wang, D.; Jiang, D.; Zhou, F.; Weng, L.; Liu, W. Comparative study of moisture corrosion to $\mathrm{WS}_{2}$ and $\mathrm{WS}_{2} / \mathrm{Cu}$ multilayer films. Surf. Coat. Technol. 2014, 247, 30-38. [CrossRef]

9. Sun, W.; Wang, L.; Wu, T.; Pan, Y.; Liu, G. Inhibited corrosion-promotion activity of graphene encapsulated in nanosized silicon oxide. J. Mater. Chem. A 2015, 3, 16843-16848. [CrossRef]

10. Yu, Y.-H.; Lin, Y.-Y.; Lin, C.-H.; Chan, C.-C.; Huang, Y.-C. High-performance polystyrene/graphene-based nanocomposites with excellent anti-corrosion properties. Polym. Chem. 2014, 5, 535-550. [CrossRef]

11. Cui, C.; Lim, A.T.O.; Huang, J. A cautionary note on graphene anti-corrosion coatings. Nat. Nanotechnol. 2017, 12, 834-835. [CrossRef] [PubMed]

12. Ali, S.; Wang, F.; Zafar, S.; Iqbal, T. Hydrothermal synthesis, characterization and raman vibrations of chalcogenide SnS nanorods. In Proceedings of the 5th Annual International Conference on Material Science 
and Engineering, Xiamen, China, 20-22 Ocotber 2017; Aleksandrova, M., Szewczyk, R., Eds.; IOP Publishing: Bristol, UK, 2018; Volume 275.

13. Gonzalez-Flores, V.E.; Mohan, R.N.; Ballinas-Morales, R.; Nair, M.T.S.; Nair, P.K. Thin film solar cells of chemically deposited SnS of cubic and orthorhombic structures. Thin Solid Film. 2019, 672, 62-65. [CrossRef]

14. Cabrera-German, D.; Garcia-Valenzuela, J.A.; Cota-Leal, M.; Martinez-Gil, M.; Aceves, R.; Sotelo-Lerma, M. Detailed characterization of good-quality $\mathrm{SnS}$ thin films obtained by chemical solution deposition at different reaction temperatures. Mater. Sci. Semicond. Process. 2019, 89, 131-142. [CrossRef]

15. Ye, J.; Qi, L.; Liu, B.; Xu, C. Facile preparation of hexagonal tin sulfide nanoplates anchored on graphene nanosheets for highly efficient sodium storage. J. Colloid Interface Sci. 2018, 513, 188-197. [CrossRef] [PubMed]

16. Reddy, N.K.; Devika, M.; Gopal, E.S.R. Review on tin (II) sulfide (SnS) material: Synthesis, properties, and applications. Crit. Rev. Solid State Mater. Sci. 2015, 40, 359-398. [CrossRef]

17. Li, Z.; Hui, S.; Yang, J.; Hua, Y. A facile strategy for the fabrication of superamphiphobic $\mathrm{MoS}_{2}$ film on steel substrates with excellent anti-corrosion property. Mater. Lett. 2018, 229, 336-339. [CrossRef]

18. Thangasamy, P.; Partheeban, T.; Sudanthiramoorthy, S.; Sathish, M. Enhanced superhydrophobic performance of $\mathrm{BN}-\mathrm{MoS}_{2}$ heterostructure prepared via a rapid, one-pot supercritical fluid processing. Langmuir 2017, 33, 6159-6166. [CrossRef]

19. Rheem, Y.; Han, Y.; Lee, K.H.; Choi, S.-M.; Myung, N.V. Synthesis of hierarchical $\mathrm{MoO}_{2} / \mathrm{MoS}_{2}$ nanofibers for electrocatalytic hydrogen evolution. Nanotechnology 2017, 28, 105605. [CrossRef]

20. Zhou, Y.; Liu, Y.; Zhao, W.; Xie, F.; Xu, R.; Li, B.; Zhou, X.; Shen, H. Growth of vertically aligned $\mathrm{MoS}_{2}$ nanosheets on a Ti substrate through a self-supported bonding interface for high-performance lithium-ion batteries: A general approach. J. Mater. Chem. A 2016, 4, 5932-5941. [CrossRef]

21. Gao, X.; Wang, X.; Ouyang, X.; Wen, C. Flexible superhydrophobic and superoleophilic $\mathrm{MoS}_{2}$ sponge for highly efficient oil-water separation. Sci. Rep. 2016, 6, 27207. [CrossRef]

22. Shi, J.; Zhang, X.; Ma, D.; Zhu, J.; Zhang, Y.; Guo, Z.; Yao, Y.; Ji, Q.; Song, X.; Zhang, Y.; et al. Substrate facet effect on the growth of mono layer $\mathrm{MoS}_{2}$ on Au foils. ACS Nano 2015, 9, 4017-4025. [CrossRef] [PubMed]

23. Hu, L.; Zhang, S.; Li, W.; Hou, B. Electrochemical and thermodynamic investigation of diniconazole and triadimefon as corrosion inhibitors for copper in synthetic seawater. Corros. Sci. 2010, 52, 2891-2896. [CrossRef]

24. Tang, Y.; Zhang, X.; Choi, P.; Xu, Z.; Liu, Q. Contributions of van der Waals interactions and hydrophobic attraction to molecular adhesions on a hydrophobic $\mathrm{MoS}_{2}$ surface in water. Langmuir 2018, 34, 14196-14203. [CrossRef] [PubMed]

25. Kozbial, A.; Gong, X.; Liu, H.; Li, L. Understanding the intrinsic water wettability of molybdenum disulfide $\left(\mathrm{MoS}_{2}\right)$. Langmuir 2015, 31, 8429-8435. [CrossRef]

26. Chen, C.; He, Y.; Xiao, G.; Xia, Y.; Li, H.; He, Z. Two-dimensional hybrid materials: $\mathrm{MoS}_{2}-\mathrm{RGO}_{\text {nanocomposites }}$ enhanced the barrier properties of epoxy coating. Appl. Surf. Sci. 2018, 444, 511-521. [CrossRef]

27. Taheri, N.N.; Ramezanzadeh, B.; Mandavian, M.; Bahlakeh, G. In-situ synthesis of Zn doped polyaniline on graphene oxide for inhibition of mild steel corrosion in $3.5 \mathrm{wt}$ \% chloride solution. J. Ind. Eng. Chem. 2018, 63, 322-339. [CrossRef]

28. Ding, R.; Zheng, Y.; Yu, H.; Li, W.; Wang, X.; Gui, T. Study of water permeation dynamics and anti-corrosion mechanism of graphene/zinc coatings. J. Alloys Compd. 2018, 748, 481-495. [CrossRef]

29. Zhang, X.; Hao, H.; Shi, Y.; Cui, J. The mechanical properties of Polyvinyl Butyral (PVB) at high strain rates. Constr. Build. Mater. 2015, 93, 404-415. [CrossRef]

30. Rappé, A.K.; Casewit, C.J.; Colwell, K.; Goddard, W.A., III; Skiff, W.M. UFF, a full periodic table force field for molecular mechanics and molecular dynamics simulations. J. Am. Chem. Soc. 1992, 114, 10024-10035. [CrossRef]

31. Tian, H.; Li, W.; Cao, K.; Hou, B. Potent inhibition of copper corrosion in neutral chloride media by novel non-toxic thiadiazole derivatives. Corros. Sci. 2013, 73, 281-291. [CrossRef]

32. Hu, C.; Li, Y.; Zhang, N.; Ding, Y. Synthesis and characterization of a poly(o-anisidine)-SiC composite and its application for corrosion protection of steel. RSC Adv. 2017, 7, 11732-11742. [CrossRef]

33. Tian, H.; Li, W.; Liu, A.; Gao, X.; Han, P.; Ding, R.; Yang, C.; Wang, D. Controlled delivery of multi-substituted triazole by metal-organic framework for efficient inhibition of mild steel corrosion in neutral chloride solution. Corros. Sci. 2018, 131, 1-16. [CrossRef] 
34. Gonzalez-Rodriguez, J.G.; Porcayo-Calderon, I.; Vazquez-Velez, E.; de la Escalera, L.M.M.; Canto, I.; Martinez, L. Use of a palm oil-based imidazoline as corrsion inhibitor for copper in $3.5 \% \mathrm{NaCl}$ solution. Int. J. Electrochem. Sci. 2016, 11, 8132-8144. [CrossRef]

35. Shi, J.M.; He, C.L.; Li, G.P.; Chen, H.Z.; Fu, X.Y.; Li, R.; Ma, G.F.; Wang, J.M. Corrosion behaviorsof pure copper and $\mathrm{Cu}-\mathrm{Ni}-\mathrm{Zn}$ alloy in $\mathrm{NaCl}$ solution and artificialsaltwater. In Proceedings of the 2nd International Conference on New Material and Chemical Industry, Sanya, China, 18-20 November 2017; Xin, S., Ed.; IOP Publishing: Bristol, UK, 2018; Volume 292.

36. Velazquez-Torres, N.; Martinez, H.; Porcayo-Calderon, I.; Vazquez-Velez, E.; Florez, O.; Campillo, B.; Gonzalez-Rodriguez, J.G.; Martinez-Gomez, L. Effect of plasma pre-oxidation on the Cu corrosion inhibition in 3.5\% NaCl by an environmentally friendly amide. Int. J. Electrochem. Sci. 2018, 13, 8915-8930. [CrossRef]

37. Wang, D.; Xiang, B.; Liang, Y.; Song, S.; Liu, C. Corrosion control of copper in 3.5 wt.\% NaCl Solution by domperidone: Experimental and theoretical study. Corros. Sci. 2014, 85, 77-86. [CrossRef]

38. Li, S.; Ma, Y.; Liu, Y.; Xin, G.; Wang, M.; Zhang, Z.; Liu, Z. Electrochemical sensor based on a three dimensional nanostructured $\mathrm{MoS}_{2}$ nanosphere-PANI/reduced graphene oxide composite for simultaneous detection of ascorbic acid, dopamine, and uric acid. RSC Adv. 2019, 9, 2997-3003. [CrossRef]

39. Sherif, E.M.; Park, S.-M. Inhibition of copper corrosion in acidic pickling solutions by N-phenyl-1,4-phenylenediamine. Electrochim. Acta 2006, 51, 4665-4673. [CrossRef]

40. Kim, H.; Lee, H.; Lim, H.-R.; Cho, H.-B.; Choa, Y.-H. Electrically conductive and anti-corrosive coating on copper foil assisted by polymer-nanocomposites embedded with graphene. Appl. Surf. Sci. 2019, 476, 123-127. [CrossRef]

41. Ramezanzadeh, B.; Bahlakeh, G.; Moghadam, M.M.; Miraftab, R. Impact of size-controlled p-phenylenediamine (PPDA)-functionalized graphene oxide nanosheets on the GO-PPDA/Epoxy anti-corrosion, interfacial interactions and mechanical properties enhancement: Experimental and quantum mechanics investigations. Chem. Eng. J. 2018, 335, 737-755. [CrossRef]

42. Kumar, N.; Manik, G. Molecular dynamics simulations of polyvinyl acetate-perfluorooctane based anti-stain coatings. Polymer 2016, 100, 194-205. [CrossRef]

43. Hong, M.-S.; Park, Y.; Kim, J.G.; Kim, K. Effect of incorporating $\mathrm{MoS}_{2}$ in organic coatings on the corrosion resistance of 316 $\mathrm{L}$ stainless steel in a 3.5\% NaCl solution. Coatings 2019, 9, 45. [CrossRef]

44. Kiran, N.U.; Dey, S.; Singh, B.P.; Besra, L. Graphene coating on copper by electrophoretic deposition for corrosion prevention. Coatings 2017, 7, 241. [CrossRef] 